\title{
Synthesis of $\alpha$-Hydroxy Fatty Acids from Fatty Acids by Intermediate $\alpha$-Chlorination with TCCA under Solvent-Free Conditions: A Way to Valorization of Waste Fat Biomasses
}

\author{
Valentina Bertolini, Marco Pallavicini, Gaurao Tibhe, Gabriella Roda, Sebastiano Arnoldi, \\ Laura Monguzzi, Marina Zoccola, Giovanna Di Nardo, Gianfranco Gilardi, and Cristiano Bolchi*
}

Cite This: ACS Omega 2021, 6, 31901-31906

Read Online

ACCESS | Lلll Metrics \& More | 回 Article Recommendations ｜ sl Supporting Information

ABSTRACT: Within food wastes, including edible and inedible parts, fat biomasses represent a significant portion, often uneconomically used or improperly disposed causing pollution issues. Interesting perspectives for their management and valorization could be opened by conversion of fatty acids (FAs), which are their main constituents, into $\alpha$-hydroxy FAs ( $\alpha$-HFAs), fine chemicals of great, but largely untapped potential, possibly due to current poor availability. Here, a simple and efficient procedure is reported to $\alpha$-chlorinate FAs with trichloroisocyanuric acid (TCCA), a green halogenating agent, under solvent-free conditions and to directly convert the resultant $\alpha$-chloro FAs, without previous purification, into $\alpha$-HFAs. The procedure was applied to stearic, palmitic, and myristic acid and, with analogous success, to their mixture, ad hoc created to simulate a FAs mixture obtainable from a fat biomass.

\section{INTRODUCTION}

Through the food supply chain, from initial agricultural production down to final household consumption, food waste amounted to 1300 million tonnes annually in 2011, including edible parts and inedible parts, namely components associated with a food that are not intended to be consumed by humans. ${ }^{1}$ In 2019, the report of Food Waste Index estimated that food waste from households, retail establishments, and the food service industry was 931 million tonnes each year. ${ }^{2}$

Among the substances found in food wastes and in inedible parts associated with food production, fatty acids (FAs) can represent significant or high weight percentages. ${ }^{3,4}$ That is the case, for instance, of peels and seeds of some fruits, of waste cooking oils, and of animal fats that include the grease of shared fleeces. In particular, this last waste biomass, annually amounting, just in EU, to more than 200 thousand tons of lowquality shorn wool, equivalent to 30 thousand tons of wool grease, is an example of inevitable byproduct, in this instance of the farming of sheep reared only for food. ${ }^{5}$ It is a biomass limited in quantity but very problematic to be managed. In fact, disposing such a waste by burning or sending it to landfill is an unsustainable practice and, on the other hand, its scouring to obtain clean wool and wool wax is costly and pollutant. Therefore, in the perspective of a circular and environmentally friendly economy, new approaches to exploit waste biomasses that, like this, have a high content of fats are highly desirable.

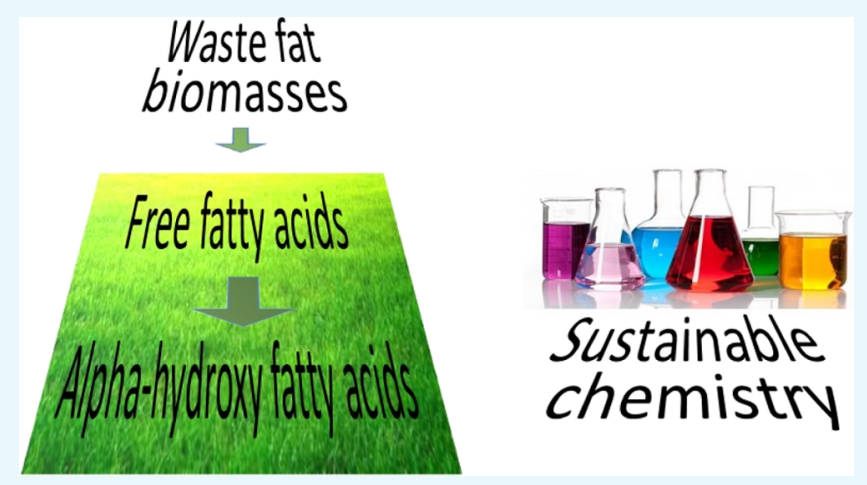

It was the peculiar and fine characteristic of wool grease, namely, the high content of $\alpha$-hydroxy FAs ( $\alpha$-HFAs) besides FAs ${ }^{6,7}$ that suggested to us that conversion of FAs into $\alpha$-HFAs could contribute to maximize the value of biomasses, rich in FAs, and to make their management profitable and sustainable. In fact, $\alpha$-HFAs are high-value fine chemicals and, unlike short chain $\alpha$-hydroxy acids, such as lactic acid, their potential is far from being fully exploited, possibly due to limited commercial availability. Indeed, the $\alpha$-carbon of FAs has rarely been targeted for chemical/biological hydroxylation. Thanks to their physical, chemical, and biological features, $\alpha$-HFAs are used in the field of cosmetics for their surfactant and antimicrobial properties, but they could be applied also in the (bio)remediation field for their surfactant and chelating ability and in the production of biodegradable polymers. ${ }^{8-12}$ Recently, they have been reported as the useful precursors of noncanonical long-chain $\alpha$-amino acids, which are of increasing interest and demand in many fields. ${ }^{13}$

Received: August 26, 2021

Accepted: October 12, 2021

Published: November 18, 2021 


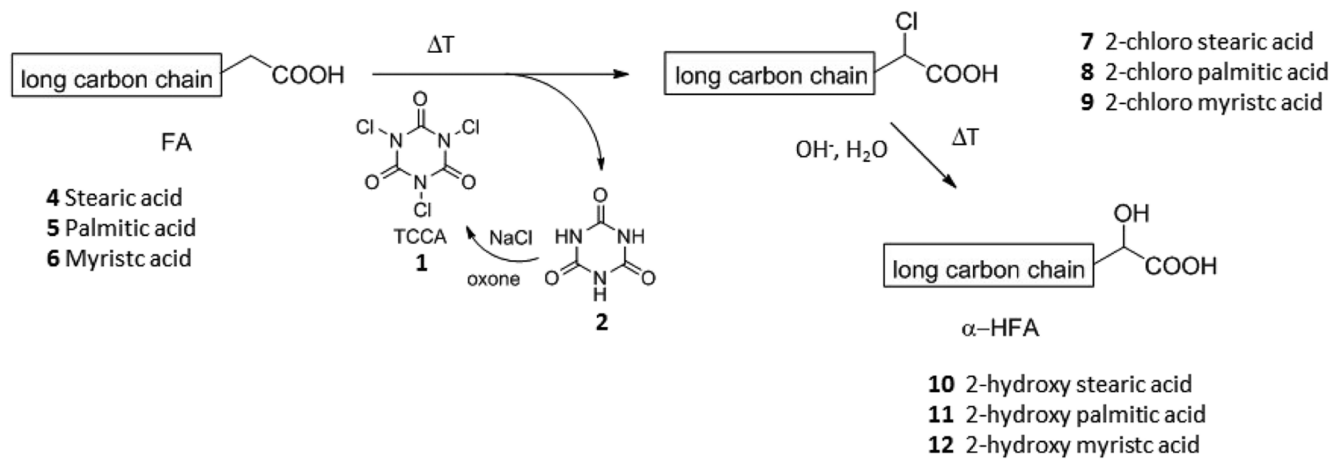

Figure 1. Conversion of long chain FAs into $\alpha$-HFAs by intermediate $\alpha$-chlorination with TCCA under solvent-free conditions.

Apart from the biocatalytic hydroxylations, ${ }^{14}$ the simplest way to convert a carboxylic acid into the corresponding $\alpha$ hydroxyacid by chemical synthesis is to $\alpha$-halogenate it and then to substitute halogen with hydroxyl. ${ }^{15}$ However, the traditional Hell-Volhard-Zelinsky $\alpha$-halogenation of carboxylic acids with molecular halogens is not environmentally friendly, and its scaling up raises many problems because halogens are hazardous, corrosive, and toxic, byproduced hydrogen halide requires special attention for waste disposal and banned or not recommended solvents are necessarily used as reaction media. ${ }^{16}$

Here, conversely, we describe an efficient and green two-step conversion of FAs into $\alpha$-HFAs by $\alpha$-chlorination, followed by the substitution of chlorine by hydroxyl, which uses, in the $\alpha$ chlorination step, an inexpensive, safe, environmentally benign, and atom-economic organohalogen like trichloroisocyanuric acid (TCCA, 1) (Figure 1). ${ }^{16-20}$ The procedure was applied to single FAs first and then to their mixture, ad hoc created to simulate a FAs mixture obtainable from wool grease and, typically, also from other waste fat biomasses.

\section{RESULTS AND DISCUSSION}

TCCA as a Chlorinating Agent. A large variety of reagents for the chlorination of organic substrates can be found in the literature. Among these, 1 stands out for many fine qualities. It is inexpensive, innocuous, environmentally benign, and stable. With respect to atom economy, TCCA is better than other chlorinating agents, such as $N$-chlorosuccinimide, $\mathrm{N}$-chlorosaccharin, chloramine-T, or 1-chlorobenzotriazole, as it is capable of transferring three chlorine atoms, corresponding to $45.5 \%$ of its mass. ${ }^{9}$ Furthermore, the byproduct of chlorination is cyanuric acid (2), which can be reused by conversion into more TCCA through a green process using $\mathrm{NaCl}$ and oxone. ${ }^{21}$ Importantly, $\mathbf{1}$ is soluble in many organic solvents, whereas $\mathbf{2}$, the chlorination byproduct, is highly insoluble. Alternatively, the water-soluble sodium dichloroisocyanurate $(\mathrm{NaDCC}, 3)$ can be used in biphasic water/organic solvent systems. Such a difference in the solubility profile between $\mathbf{1}$ and $\mathbf{2}$ allows chlorination to be driven to completion in suitably selected solvents and it facilitates the quantitative removal of $\mathbf{2}$ in the reaction work-up by simple filtration. 1 or 3 efficiently chlorinates the nitrogen of primary and secondary amines and amides, yielding intermediates whose dehydrohalogenation gives access to synthetically useful unsaturated derivatives, such as nitriles, ${ }^{22,23}$ imines, ${ }^{24}$ enamines, ${ }^{25}$ azo-compounds, ${ }^{26}$ isocyanates, ${ }^{27}$ and $\alpha, \beta$-unsaturated $\alpha$-amino esters. ${ }^{28}$ C-Halogenation of alkenes, ${ }^{16,29}$ aromatics, ${ }^{17,19,30,31}$ alkyl aromatic hydrocarbons, ${ }^{19}$ and carbonyl compounds ${ }^{16,17,19}$ is the other important chapter of the applications of $\mathbf{1}$ as a halogenating reagent in organic synthesis. In the development of new green technologies, the potential of 1 as a halogenating agent relies not only on its intrinsic environmental benignity but also on its suitability for newly conceived more efficient and sustainable procedures. Recent examples are the amplification of the electrophilicity of TCCA chlorine by visible-light catalysis to chlorinate electrondeficient arenes and heteroarenes under mild conditions, ${ }^{20}$ solvent-free chlorination of aromatics and carbonyl compounds in the solid state by ball milling, ${ }^{17}$ and conversion of methane into chloromethane by mechanochemical activation. ${ }^{32}$ Based on these literature premises and on our experience with 1 use, we planned the $\alpha$-chlorination of FAs with 1 under solvent-free conditions, at temperatures slightly higher than their melting points.

$\boldsymbol{\alpha}$-Chlorination of FAs. Three saturated long-chain FAs were chosen as substrates because the main exponents, besides $\alpha$-HFAs, of carboxylic acids in wool wax are as follows: octadecanoic (stearic) acid (4), hexadecanoic (palmitic) acid (5), and tetradecanoic (myristic) acid (6). To our knowledge, the only example of FAs $\alpha$-chlorination is that of 4 by treatment with $\mathrm{Cl}_{2}$ at $150{ }^{\circ} \mathrm{C}$ for about $1 \mathrm{~h}$ in the presence of chlorosulfonic acid (3 mol \%) as a catalyst and 7,7,8,8tetracyanoquinodimethane (TCNQ $0.5 \mathrm{~mol} \%$ ) as a free radical inhibitor. ${ }^{33}$ According to this procedure, $\alpha$-chlorostearic acid (4a) was isolated with $88 \%$ yield by crystallization from acetonitrile. Although not exemplified, the same reaction was run with all of the even-chain saturated acids between $\mathrm{C}_{6}$ and $\mathrm{C}_{16}$ by the same researchers claiming essentially identical results. As explained above, our approach was to avoid the use of chlorine by replacing it with much more acceptable 1 under solvent-free conditions. Slightly exceeding 1 (1.4 equiv) and catalytic $\mathrm{PCl}_{3}$ (0.1 equiv), to generate, according to the generally accepted mechanism of the Hell-Volhard-Zelinsky $\alpha$-halogenation of carboxylic acids, the necessary initial small amount of the acid chloride in enolic form, were used in all the experiments while varying time and temperature. Typically, the FA ( $35 \mathrm{mmol})$ was heated to melt $\left(80^{\circ} \mathrm{C}\right)$ under stirring and nitrogen in a flask wrapped with foil to exclude light. $1 \mathrm{~h}$ after adding catalytic $\mathrm{PCl}_{3}(1.2 \mathrm{mmol}), 1(16.3 \mathrm{mmol})$ was added portion-wise over $30 \mathrm{~min}$ while heating was continued. The screening of temperatures ranging between 80 and $100{ }^{\circ} \mathrm{C}$ and of times ranging between 3 and $24 \mathrm{~h}$ indicated $80^{\circ} \mathrm{C}$ and $24 \mathrm{~h}$ as the best reaction conditions to be applied. At the end, ethyl acetate was added to the reaction mixture at room temperature to precipitate cyanuric acid, which was removed by filtration. The filtrate was washed with aqueous sodium metabisulfite, to 
destroy the excess of $\mathbf{1}$, and then with brine. The concentration of the filtrate gave the crude $\alpha$-chlorinated FAs 2-chlorostearic acid (7), 2-chloropalmitic acid (8), and 2-chloromyristic acid (9) as white solids with $96-97 \%$ yields. Gas chromatography (GC)-flame ionization detector (FID) analyses indicated purities ranging between 85 and $92 \%$ consistently with proton and carbon NMR spectra, all showing a largely predominant constituent with a prominent signal of chlorinated methine in the 2-position of the chain having, in the H NMR spectrum, the expected doublet of doublet multiplicity and near oneproton integration. GC-FID analyses evidenced a main impurity, which was reasonably identified, on the basis of the GC-mass spectrometry (MS) spectra and of the minor signals in the $\mathrm{H}$ NMR spectra, as a minimal amount of the dichlorinated product. The catalytic amount of $\mathrm{PCl}_{3}$ can be reduced but slowing the reaction. Under the same abovementioned reaction conditions, 50\% conversion of 4 into 7 was observed using 0.03 instead of 0.1 equiv of $\mathrm{PCl}_{3}$.

$\alpha$-Hydroxylation of FAs. The conversion into $\alpha$-hydroxy acids was performed on the three abovementioned crude $\alpha$ chlorinated FAs by treatment with $\mathrm{KOH}$ (4 equiv) in water under reflux for $24 \mathrm{~h}$. Crude $\alpha$-hydroxylated FAs were precipitated from the reaction mixture as white solids by the acidification to $\mathrm{pH} 1$ at room temperature in quantities higher than $90 \%$ of the theoretical amounts, calculated on initial 35 mmol FA, and with purities, determined using GC, ranging between 78 and $88 \%$. Trituration of the crude solids in different solvents, such as methanol, ethanol, 2-propanol, CPME, hexane, or acetonitrile, at room temperature was enough to achieve $>95 \%$ purities. The best results in terms of the final yield (64-68\%) and purity (99-100\%) were obtained by trituration in acetonitrile, but the procedure is susceptible of further improvement both for yield and solvent choice.

$\alpha$-Chlorination and Hydroxylation of FAs Mixtures. The successive step of the investigation was to apply the abovementioned chlorination and hydroxylation procedures starting from an equimolar mixture of the three FAs 4, 5, and 6 with the intent to mimic a mixture of long chain FAs obtainable by the hydrolysis of wool wax esters and subsequent separation, through selective extraction, ${ }^{6}$ from the very long chain and $\alpha$-hydroxy long chain FAs. As expected on the basis of the similar reactivity shown by 4,5 , and 6 , the equimolar mixture of 4,5 , and 6 , when submitted to chlorination with TCAA and to successive hydroxylation, behaved as the three single FAs. In fact, it provided, with $92 \%$ yield, an $85 \%$ pure near equimolar mixture of 7,8 , and 9 in which the remaining $15 \%$ was a near equimolar mixture of the supposed corresponding dichlorinated acids. Then, the crude mixture of the three $\alpha$-chlorinated acids yielded, with $100 \%$ purity and $74.2 \%$ yield, a mixture of 10,11 , and 12 , which was, reasonably as a consequence of the final trituration in acetonitrile, slightly richer in $10(34.6 \%)$ and $11(36.7 \%)$ and poorer in 12 (28.6\%). In the two steps, the recovered amounts and the purities are in line with the data obtained for the single FAs and $74.2 \%$ is the overall yield of the conversion of the mixed FAs into $\alpha$-HFAs.

\section{CONCLUSIONS}

An efficient and environmentally benign procedure was developed to convert long-chain saturated FAs (stearic, palmitic, and myristic acid) into $\alpha$-HFAs without purifying the intermediate $\alpha$-chlorinated FAs. This was possible because of a green halogenating agent, such as TCCA, which proved to be able, used in slight excess, to quantitatively $\alpha$-chlorinate melted FAs under solvent-free conditions with the concomitant minimal formation of a dichlorinated product. Therefore, the successive treatment of crude halogenated FAs with aqueous $\mathrm{KOH}$ under reflux could provide the corresponding $\alpha$ HFAs, isolable pure by simple precipitation from the acidified reaction medium and successive trituration in a suitable solvent. The robustness of the whole two-step procedure was demonstrated by its successful application to the equimolar mixture of the three FAs, which were converted into the corresponding $\alpha$-HFAs with a near unaltered molar ratio.

The process, designed to valorize the saturated FAs of wool wax and to indirectly make the waste wool management more sustainable, provides appealing opportunities for converting other FAs and FA mixtures, recoverable from lipid-based waste biomasses, into valuable fine chemicals of great potential, such as $\alpha$-HFAs.

\section{EXPERIMENTAL SECTION}

Materials and Methods. Stearic acid, palmitic acid, myristic acid, 1, and phosphorus trichloride were purchased from Sigma and used without further purification. ${ }^{1} \mathrm{H}-\mathrm{NMR}$ and ${ }^{13} \mathrm{C}-\mathrm{NMR}$ spectrums were recorded in $\mathrm{CDCl}_{3}, \mathrm{DMSO}-d_{6}$, and $\mathrm{CD}_{3} \mathrm{OD}$ at 300 and $75 \mathrm{MHz}$, respectively, with a Varian Mercury 300 spectrometer and elaborated with Mnova software. Chemical shifts are reported in ppm relative to a residual solvent as internal standard.

GC/FID analyses were performed using a gas chromatograph Trace GC with a FID and autosampler AS2000 (Thermo Fisher). Before the analysis, the sample $(5 \mathrm{mg}$ ) was derivatized, as methyl ester, using a $500 \mu \mathrm{L}$ of $\mathrm{HCl} 3 \mathrm{M}$ solution in $\mathrm{MeOH}$ and left in the oven at $55{ }^{\circ} \mathrm{C}$ overnight. Hexane $(1.2 \mathrm{~mL})$ was then used as an extraction solvent, and 1 $\mathrm{mL}$ was transferred into a $2 \mathrm{~mL}$ vial and analyzed. Chromatographic separation was carried out on a DB-5 MS UI fused silica capillary column ( $30 \mathrm{~m}, 0,25 \mathrm{~mm}$ I.D., $0,25 \mu \mathrm{m}$ film thickness, Agilent). The GC-FID system was operated under the following conditions: injection temperature $280{ }^{\circ} \mathrm{C}$ (split mode 30:1); the initial column temperature was $180^{\circ} \mathrm{C}$ and was subsequently increased to $280{ }^{\circ} \mathrm{C}$ at a rate of $5{ }^{\circ} \mathrm{C} /$ min. Helium was used as the carrier gas at a flow rate of 1.0 $\mathrm{mL} / \mathrm{min}$. The FID was operated at $300{ }^{\circ} \mathrm{C}$.

GC/MS analyses were performed on a Varian-Agilent 3900 gas chromatograph with an ion trap mass selective detector Saturn 2100T (Varian-Agilent) and autosampler CP8400. Chromatographic separation was carried out on a HP-1 MS UI fused silica capillary column $(12 \mathrm{~m} \times 0.18 \mathrm{~mm}$ i.d., film thickness $0.18 \mu \mathrm{m}$, Agilent). The GC/MS system was operated under the following conditions: injection temperature $250{ }^{\circ} \mathrm{C}$ (split mode 50:1); interface transfer line $300^{\circ} \mathrm{C}$; and the initial column temperature $150^{\circ} \mathrm{C}$, which was subsequently increased to $250{ }^{\circ} \mathrm{C}$ at a rate of $5{ }^{\circ} \mathrm{C} / \mathrm{min}$. Helium was used as the carrier gas at a flow rate of $0.9 \mathrm{~mL} / \mathrm{min}$. MS analysis was performed in a SCAN MODE $(35 / 650 \mathrm{~m} / z)$ operated in a chemical ionization mode with methanol as a reactant gas and an emission current of $10 \mu \mathrm{A}$. The injection volume was $1 \mu \mathrm{L}$ with a solvent delay of $2 \mathrm{~min}$.

High resolution electrospray mass spectra were acquired with Q-TOF Synapt G2 Si (WATERS). The percent of conversion, selectivity, and the identity of the compounds were determined using GC/FID, GC/MS, and high-resolution mass spectrometry (HRMS) analysis. 
General Procedure for $\boldsymbol{\alpha}$-Chlorination of FAs. In a round-bottom flask wrapped in aluminum foil, the FA (35 $\mathrm{mmol})$ was heated under magnetic stirring at $80{ }^{\circ} \mathrm{C}$ until melting. The liquid mass was added of $\mathrm{PCl}_{3}$ (1.2 mmol, 104 $\mu \mathrm{L})$ and left reacting for $1 \mathrm{~h}$. TCCA ( $16.3 \mathrm{mmol}, 3.78 \mathrm{~g})$ was slowly added over $30 \mathrm{~min}$. The mixture was then stirred for 24 $\mathrm{h}$ at $80{ }^{\circ} \mathrm{C}$. After this time, the reaction mixture was cooled down at room temperature, and ethyl acetate was added: a white precipitate was formed. The solid was then removed by filtration, and the filtrate was washed with a solution of sodium metabisulfite $(10 \% \mathrm{w} / \mathrm{v})$ and with brine. The organic layer was collected, dried over sodium sulfate, and concentrated under vacuum to give the desired alpha-chloro acid.

Synthesis of 2-Chloro Stearic Acid (7). Obtained as a white solid crude $(10.83 \mathrm{~g}, 97.0 \%$ of theoretical amount): $\mathrm{mp}$ $62.2{ }^{\circ} \mathrm{C}$, Rf (dichloromethane/methanol 9:1) $=0.55,{ }^{1} \mathrm{H}$ NMR $\left(300 \mathrm{MHz}, \mathrm{DMSO}-d_{6}\right): \delta 4.42(\mathrm{dd}, J=7.7,5.9 \mathrm{~Hz}, 1 \mathrm{H}), 1.98$ $-1.68(\mathrm{~m}, 2 \mathrm{H}), 1.22(\mathrm{~s}, 28 \mathrm{H}), 0.83(\mathrm{t}, J=6.7 \mathrm{~Hz}, 3 \mathrm{H}) .{ }^{13} \mathrm{C}$ $\mathrm{NMR}\left(75 \mathrm{MHz}, \mathrm{CDCl}_{3}\right): \delta 176.02,57.08,34.71,31.91,29.67$, $29.65,29.62,29.57,29.46,29.34,29.28,29.17,28.80,25.87$, 22.67, 14.09. GC-MS: $[\mathrm{M}+\mathrm{H}]=333.5$, GC-FID: $R_{\mathrm{t}}=12.65$ min, conversion $=100 \%$, purity $=91.7 \%$.

Synthesis of 2-Chloro Palmitic Acid (8). Obtained as a white solid crude $(9.81 \mathrm{~g}, 96.4 \%$ of the theoretical amount): $\mathrm{mp} 55.7{ }^{\circ} \mathrm{C}$, Rf (dichloromethane/methanol 98:2) $=0.6,{ }^{1} \mathrm{H}$ NMR $\left(300 \mathrm{MHz}, \mathrm{DMSO}-d_{6}\right): \delta 4.42(\mathrm{dd}, J=7.7,5.9 \mathrm{~Hz}, 1 \mathrm{H})$, 2.01-1.68 (m, $2 \mathrm{H}), 1.27(\mathrm{~s}, 24 \mathrm{H}), 0.83(\mathrm{t}, J=6.6 \mathrm{~Hz}, 3 \mathrm{H})$. ${ }^{13} \mathrm{C} \mathrm{NMR}\left(75 \mathrm{MHz}, \mathrm{CDCl}_{3}\right): \delta 175.53,57.07,34.73,31.90$, 29.66, 29.65, 29.63, 29.61, 29.56, 29.46, 29.34, 29.27, 28.79, 25.86, 22.67, 14.09. GC-MS: $[\mathrm{M}+\mathrm{H}]=305.5$, GC-FID: $R_{\mathrm{t}}=$ $9.58 \mathrm{~min}$, conversion $=100 \%$, purity $=89.0 \%$.

Synthesis of 2-Chloro Myristic Acid (9). Obtained as a white solid crude $(8.84 \mathrm{~g}, 96.1 \%$ of the theoretical amount): mp $43.7{ }^{\circ} \mathrm{C}$, Rf (dichloromethane/methanol 98:2) $=0.4,{ }^{1} \mathrm{H}$ NMR $\left(300 \mathrm{MHz}\right.$, DMSO- $\left.d_{6}\right): \delta 4.42(\mathrm{dd}, J=7.7,5.9 \mathrm{~Hz}, 1 \mathrm{H})$, $1.99-1.67(\mathrm{~m}, 2 \mathrm{H}), 1.49-1.13(\mathrm{~m}, 20 \mathrm{H}), 0.84(\mathrm{t}, J=6.7 \mathrm{~Hz}$, $2 \mathrm{H}) .{ }^{13} \mathrm{C}$ NMR $\left(75 \mathrm{MHz}, \mathrm{CDCl}_{3}\right): \delta 175.54,57.07,34.73$, $31.89,29.61,29.56,29.52,29.50,29.49,29.45,29.32,29.27$, 29.24, 28.79, 25.86, 22.67, 14.09. GC-MS: $[\mathrm{M}+\mathrm{H}]=277.3$, GC-FID: $R_{\mathrm{t}}=6.728 \mathrm{~min}$, conversion $=100 \%$, purity $=84.6 \%$

Synthesis of 2-Chloro Stearic Acid, 2-Chloro Palmitic Acid, and 2-Chloro Myristic Acid Mixture. Obtained as a white solid crude (9.33 g, 91.7\% of the theoretical amount) from $35 \mathrm{mmol}$ of an equimolar mixture of 4,5 , and 6 according to the general procedure adopted for the single FAs: mp $40.9^{\circ} \mathrm{C}$, GC-FID: $R_{\mathrm{t}}=6.717 \mathrm{~min}, 9.537 \mathrm{~min}, 12.622 \mathrm{~min}$, conversion $=100 \%$, purity $=85.5 \%$.

General Procedure for the Conversion of $\alpha$-chloro FAs into $\boldsymbol{\alpha}$-HFAs. In a round-bottom flask, $\mathrm{KOH}(140 \mathrm{mmol}$, $7.85 \mathrm{~g})$ and water $(200 \mathrm{~mL})$ were stirred at $80{ }^{\circ} \mathrm{C}$ for $30 \mathrm{~min}$. The crude 2-chloro FA resultant from the chlorination step was added to the $\mathrm{KOH}$ water solution, and the mixture was refluxed for $24 \mathrm{~h}$. Then, the mixture was cooled down at room temperature and the $\mathrm{pH}$ was adjusted to 1 using $\mathrm{HCl} 1 \mathrm{M}$. A white solid precipitated. The mixture was filtered, and the solid was recovered. After purification by trituration with acetonitrile, in a $1: 3$ ratio, the desired $\alpha$-HFA was obtained as a white solid.

Synthesis of 2-Hydroxy Stearic Acid (10). Obtained as a white solid in $68 \%$ yield: $\mathrm{mp} 90.8{ }^{\circ} \mathrm{C}$, $\mathrm{Rf}$ (dichloromethane/ methanol 9:1) $=0.62,{ }^{1} \mathrm{H}$ NMR $\left(300 \mathrm{MHz}\right.$, DMSO- $\left.d_{6}\right): \delta 3.88$ (dd, $J=7.6,4.5 \mathrm{~Hz}, 1 \mathrm{H}$ ), 3.38 (bs, $1 \mathrm{H}$, exchange with $\mathrm{D}_{2} \mathrm{O}$ ), $1.64-1.37(\mathrm{~m}, 2 \mathrm{H}), 1.25(\mathrm{~s}, 28 \mathrm{H}), 0.83(\mathrm{t}, J=6.7 \mathrm{~Hz}, 3 \mathrm{H})$.
${ }^{13} \mathrm{C}$ NMR (75 MHz, $\left.\mathrm{CD}_{3} \mathrm{OD}\right): \delta 176.62,70.03,34.00,31.64$, $29.35,29.33,29.26,29.21,29.05,24.70,22.31,13.01$. ESI negative HRMS: calcd for $\mathrm{C}_{18} \mathrm{H}_{35} \mathrm{O}_{3}[\mathrm{M}-\mathrm{H}]^{-}, \mathrm{m} / z$, 299.2586; found, 299.2585, GC-FID: $R_{\mathrm{t}}=12.142 \mathrm{~min}$, purity $=98.9 \%$.

Synthesis of 2-Hydroxy Palmitic Acid (11). Obtained as a white solid in $64 \%$ yield: $\mathrm{mp} 85.7^{\circ} \mathrm{C}$, Rf (dichloromethane/ methanol 9:1) $=0.53,{ }^{1} \mathrm{H}$ NMR $\left(300 \mathrm{MHz}\right.$, DMSO- $\left.d_{6}\right): \delta 3.88$ (dd, $J=7.6,4.6 \mathrm{~Hz}, 1 \mathrm{H}), 3.30$ (bs, $1 \mathrm{H}$, exchange with $\mathrm{D}_{2} \mathrm{O}$ ), $1.85-1.45(\mathrm{~m}, 2 \mathrm{H}), 1.22(\mathrm{~s}, 24 \mathrm{H}), 0.85(\mathrm{t}, J=6.7 \mathrm{~Hz}, 3 \mathrm{H})$. ${ }^{13} \mathrm{C}$ NMR (75 MHz, CD 3 OD): $\delta 176.59,70.02,34.00,31.65$, 29.36, 29.34, 29.26, 29.20, 29.05, 24.70, 22.30, 13.01. ESI negative HRMS: calcd for $\mathrm{C}_{16} \mathrm{H}_{31} \mathrm{O}_{3}[\mathrm{M}-\mathrm{H}]^{-}, \mathrm{m} / z$, 271.2273; found, 271.2272. GC-FID: $R_{\mathrm{t}}=9.062 \mathrm{~min}$, purity $=99.4 \%$.

Synthesis of 2-Hydroxy Myristic Acid (12). Obtained as a white solid in $66 \%$ yield: $\mathrm{mp} 83.5{ }^{\circ} \mathrm{C}$, Rf (dichloromethane/ methanol 9:1) $=0.46,{ }^{1} \mathrm{H}$ NMR $(300 \mathrm{MHz}$, DMSO-d $): \delta 3.88$ (dd, $J=7.6,4.6 \mathrm{~Hz}, 1 \mathrm{H}), 1.66-1.42(\mathrm{~m}, 2 \mathrm{H}), 1.25(\mathrm{~s}, 20 \mathrm{H})$, $0.83(\mathrm{~m}, 3 \mathrm{H}) .{ }^{13} \mathrm{C}$ NMR (75 MHz, $\left.\mathrm{CD}_{3} \mathrm{OD}\right): \delta 177.11,70.23$, $34.15,31.71,29.45,29.42,29.37,29.31,29.17,29.13,24.81$, 22.37, 13.15 ESI negative HRMS: calcd for $\mathrm{C}_{14} \mathrm{H}_{27} \mathrm{O}_{3}[\mathrm{M}-$ $\mathrm{H}]^{-}, \mathrm{m} / z, 243.1960$; found, 243.1958, GC-FID: $R_{\mathrm{t}}=6.297$ min, purity $=99.0 \%$.

Synthesis of 2-Hydroxy Stearic Acid, 2-Hydroxy Palmitic Acid, and 2-Hydroxy Myristic Acid Mixture. It was obtained as a white solid in $74.2 \%$ yield from the mixture of crude $\alpha$-chloro FAs, which was in turn obtained from 35 mmol of equimolar mixture of 4,5 , and 6 , according to the procedure adopted for the hydroxylation of single crude $\alpha$ chloro FAs: $\mathrm{mp} 69.3{ }^{\circ} \mathrm{C}$, GC-FID: $R_{\mathrm{t}}=6.295 \mathrm{~min}, 9.050 \mathrm{~min}$, $12.120 \mathrm{~min}$, purity $=100 \%$.

\section{ASSOCIATED CONTENT}

\section{Supporting Information}

The Supporting Information is available free of charge at https://pubs.acs.org/doi/10.1021/acsomega.1c04640.

${ }^{1} \mathrm{H}$ NMR, ${ }^{13} \mathrm{C}$ NMR spectrums, GC-FID, GC-MS, and HRMS analyses (PDF)

\section{AUTHOR INFORMATION}

\section{Corresponding Author}

Cristiano Bolchi - Dipartimento di Scienze Farmaceutiche, Università degli Studi di Milano, I-20133 Milano, Italy; (1) orcid.org/0000-0002-6726-9501; Email: cristiano.bolchi@unimi.it

\section{Authors}

Valentina Bertolini - Dipartimento di Scienze Farmaceutiche, Università degli Studi di Milano, I-20133 Milano, Italy

Marco Pallavicini - Dipartimento di Scienze Farmaceutiche, Università degli Studi di Milano, I-20133 Milano, Italy; (1) orcid.org/0000-0003-3344-484X

Gaurao Tibhe - Dipartimento di Scienze Farmaceutiche, Università degli Studi di Milano, I-20133 Milano, Italy

Gabriella Roda - Dipartimento di Scienze Farmaceutiche, Università degli Studi di Milano, I-20133 Milano, Italy

Sebastiano Arnoldi - Dipartimento di Scienze Farmaceutiche, Università degli Studi di Milano, I-20133 Milano, Italy

Laura Monguzzi - Dipartimento di Scienze Farmaceutiche, Università degli Studi di Milano, I-20133 Milano, Italy 
Marina Zoccola - Italian National Research Council, I-13900 Biella, Italy; orcid.org/0000-0002-5356-4817

Giovanna Di Nardo - Dipartimento di Scienze della Vita e Biologia dei Sistemi, Università di Torino, I-10113 Torino, Italy

Gianfranco Gilardi - Dipartimento di Scienze della Vita e Biologia dei Sistemi, Università di Torino, I-10113 Torino, Italy

Complete contact information is available at:

https://pubs.acs.org/10.1021/acsomega.1c04640

\section{Author Contributions}

The manuscript was written through contributions of all authors. All authors have given approval to the final version of the manuscript.

\section{Notes}

The authors declare no competing financial interest.

\section{ACKNOWLEDGMENTS}

Financial support was provided by the Cariplo Foundation under grant 2018-2781: FALstaff project: FAs from Lanolin. The authors acknowledge support from the University of Milan through the APC initiative.

\section{ABBREVIATIONS}

FA, fatty acid; $\alpha$-HFA, alpha-hydroxy fatty acid; TCCA, trichloroisocyanuric acid.

\section{REFERENCES}

(1) Gustavsson, J.; Cederberg, C.; Sonesson, U.; Van Otterdijk, R.; Meybeck, A. Global Food Losses and Food Waste: Extent, Causes and Prevention; Food and Agriculture Organization of the United Nations (FAO): Rome, 2011.

(2) United Nations Environment Programme. Food Waste Index Report 2021; United Nations Environment, 2021.

(3) Sanchez-Vazquez, S. A.; Hailes, H. C.; Evans, J. R. G. Hydrophobic Polymers from Food Waste: Resources and Synthesis. Polym. Rev. 2013, 53, 627-694.

(4) Sawangkeaw, R.; Ngamprasertsith, S. A Review of Lipid-Based Biomasses as Feedstocks for Biofuels Production. Renew. Sustain. Energy Rev. 2013, 25, 97-108.

(5) Petek, B.; Logar, R. M. Management of Waste Sheep Wool as Valuable Organic Substrate in European Union Countries. J. Mater. Cycles Waste Manag. 2021, 23, 44-54.

(6) Paal, M.; Schmucker, R.; Rudolph, M. Process for Separating and Purifying Fatty Acids and Alpha-Hydroxy Fatty Acids. EP 555776 A1, 1993.

(7) Motiuk, K. Wool Wax Acids: A Review. J. Am. Oil Chem. Soc. 1979, 56, 91-97.

(8) Schmucker, R.; Paal, M.; Sauermann, G.; Schreiner, V.; Traupe, B.; Eigener, U. Utilisation of fatty alpha-hydroxy acids. EP 0556660 B1, 1997.

(9) Erlenmayer, H.; Bossardt, A. A.; Theilheimer, W. Comparative flotation experiments with fatty acids and alpha-hydroxy fatty acids as collectors. Helv. Chim. Acta 1944, 27, 1429-1432.

(10) Bustamante, M.; Duran, N.; Diez, M. C. Biosurfactants are useful tools for the bioremediation of contaminated soil: a review. J. Soil Sci. Plant Nutr. 2012, 12, 667-687.

(11) Mnif, I.; Ghribi, D. Glicolipid biosurfactants: main properties and potential applications in agriculture and food industry. J. Sci. Food Agric. 2016, 96, 4310-4320.

(12) Liu, Y.; Song, L.; Feng, N.; Jiang, W.; Jin, Y.; Li, X. Recent advances in the synthesis of biodegradable polyesters by sustainable polymerization: lipase-catalyzed polymerization. RSC Adv. 2020, 10, 36230-36240.
(13) Dennig, A.; Blaschke, F.; Gandomkar, S.; Tassano, E.; Nidetzky, B. Preparative Asymmetric Synthesis of Canonical and Non-canonical $\alpha$-amino Acids Through Formal Enantioselective Biocatalytic Amination of Carboxylic Acids. Adv. Synth. Catal. 2019, 361, $1348-1358$.

(14) Cao, Y.; Zhang, X. Production of Long-Chain Hydroxy Fatty Acids by Microbial Conversion. Appl. Microbiol. Biotechnol. 2013, 97, $3323-3331$.

(15) Wenkert, E.; Alonso, M. E.; Buckwalter, B. L.; Sanchez, E. L. Short Syntheses of Furan and Catechol Derivatives. A Synthesis of Hydrourushiol. J. Am. Chem. Soc. 1983, 105, 2021-2029.

(16) Mendonça, G. F.; de Mattos, M. C. S. Green Chlorination of Organic Compounds Using Trichloroisocyanuric Acid (TCCA). Curr. Org. Synth. 2013, 10, 820-836.

(17) Mishra, A. K.; Nagarajaiah, H.; Moorthy, J. N. Trihaloisocyanuric Acids as Atom-Economic Reagents for Halogenation of Aromatics and Carbonyl Compounds in the Solid State by Ball Milling. Eur. J. Org. Chem. 2015, 2015, 2733-2738.

(18) Achar, T. K.; Bose, A.; Mal, P. Mechanochemical synthesis of small organic molecules. Beilstein J. Org. Chem. 2017, 13, 1907-1931.

(19) Gaspa, S.; Carraro, M.; Pisano, L.; Porcheddu, A.; De Luca, L. Trichloroisocyanuric Acid: a Versatile and Efficient Chlorinating Agent and Oxidizing Reagent. Eur. J. Org. Chem. 2019, 2019, 35443552.

(20) Rogers, D. A.; Bensalah, A. T.; Espinosa, A. T.; Hoerr, J. L.; Refai, F. H.; Pitzel, A. K.; Alvarado, J. J.; Lamar, A. A. Amplification of Trichloroisocyanuric Acid (TCCA) Reactivity for Chlorination of Arenes and Heteroarenes via Catalytic Organic Dye Activation. Org. Lett. 2019, 21, 4229-4233.

(21) Tozetti, S. D. F.; de Almeida, L. S.; Esteves, P. M.; de Mattos, M. C. S. Trihaloisocyanuric Acids/NaX: an Environmentally Friendly System for Vicinal Dihalogenation of Alkenes without Using Molecular Halogen. J. Braz. Chem. Soc. 2007, 18, 675-677.

(22) Zagami, M.; Binda, M.; Piccolo, O.; Straniero, V.; Valoti, E.; Pallavicini, M. From Pregabalin to rac-Cyano-5-methylhexanoic Acid: an Easy Conversion Which Valorizes Waste Pregabalin Enantiomer. Tetrahedron Lett. 2012, 53, 6075-6077.

(23) Bolchi, C.; Valoti, E.; Straniero, V.; Ruggeri, P.; Pallavicini, M. From 2-Aminomethyl-1,4-benzodioxane Enantiomers to Unichiral 2Cyano and 2-Carbonyl-Substituted Benzodioxanes via Dichloroamine. J. Org. Chem. 2014, 79, 6732-6737.

(24) Bolchi, C.; Pallavicini, M.; Fumagalli, L.; Straniero, V.; Valoti, E. One-Pot Racemization Process of 1-Phenyl-1,2,3,4-tetrahydroisoquinoline.: A Key Intermediate for the Antimuscarinic Agent Solifenacin. Org. Process Res. Dev. 2013, 17, 432-437.

(25) Pallavicini, M.; Bolchi, C.; Fumagalli, L.; Piccolo, O.; Valoti, E. Highly Efficient Racemisation of a Key Intermediate of the Antibiotic Moxifloxacin. Tetrahedron: Asymmetry 2011, 22, 379-380.

(26) Su, Y.; Liu, X.; Yu, J.; Cao, G.; Zhang, R.; Zhao, Y.; Huang, D.; Wang, K.-H.; Huo, C.; Hu, Y. Trichloroisocyanuric Acid Mediated Oxidative Dehydrogenation of Hydrazines: A Practical Chemical Oxidation To Access Azo Compounds. Synthesis 2020, 52, 11031112.

(27) Bolchi, C.; Pallavicini, M.; Binda, M.; Fumagalli, L.; Valoti, E. From Carnitinamide to 5-Aminomethyl-2-oxazolidinones. Tetrahedron: Asymmetry 2012, 23, 217-220.

(28) Pallavicini, M.; Bolchi, C.; Fumagalli, L.; Piccolo, O.; Valoti, E. A Highly Efficient Method for the $\alpha, \beta$-Dehydrogenation of $\alpha$-Amino Esters and $\alpha$-Amino- $\beta$-Diesters. Tetrahedron Lett. 2010, 51, 55405542.

(29) Crespo, L. T. C.; da Ribeiro, R. S.; de Mattos, M. C. S.; Esteves, P. M. Halofluorination of Alkenes Using Trihaloisocyanuric Acids and HF•Pyridine. Synthesis 2010, 2010, 2379-2382.

(30) de Almeida, L. S.; Esteves, P. M.; de Mattos, M. C. S. A New Regioselective Bromination of Activated Aromatic Rings. Synthesis 2006, 2006, 0221-0223.

(31) Mendonça, G. F.; Bastos, A. R.; Boltz, M.; Louis, B.; Pale, P.; Esteves, P. M.; de Mattos, M. C. S. Electrophilic Chlorination of 
Arenes with Trichloroisocyanuric Acid over Acid Zeolites. Appl. Catal., A 2013, 460-461, 46-51.

(32) Bilke, M.; Losch, P.; Vozniuk, O.; Bodach, A.; Schüth, F. Methane to Chloromethane by Mechanochemical Activation: A Selective Radical Pathway. J. Am. Chem. Soc. 2019, 141, 1121211218.

(33) Crawford, R. J. An Improved $\alpha$-Chlorination of Carboxylic Acids. J. Org. Chem. 1983, 48, 1364-1366. 